\title{
Situs ambiguous and absence of the inferior vena cava: An extremely rare cause of femoral hemodialysis catheter...
}

Article in Clinical nephrology · September 2015

DOI: $10.5414 / C N 108513 \cdot$ Source: PubMed

CITATIONS

0

4 authors, including:

Pedro Vieira

Hospital Central do Funchal

11 PUBLICATIONS 1 CITATION

SEE PROFILE
READS

20

Nuno Guimarães Rosa

Hospital Central do Funchal

11 PUBLICATIONS 19 CITATIONS

SEE PROFILE 


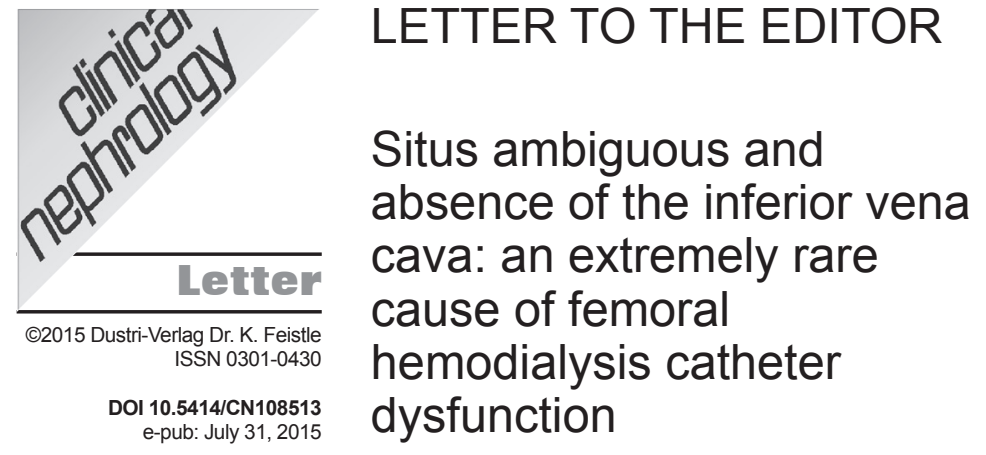

Pedro Vieira1', Nuno G. Rosa1', Guida Castanha $^{2}$, and Gil Silva ${ }^{1}$

${ }^{1}$ Serviço de Nefrologia, and ${ }^{2}$ Serviço de Radiologia, Hospital Central do Funchal, Funchal, Portugal

Sir, - Hemodialysis catheter dysfunction (CDys) has been defined by Kidney Disease Outcomes Quality Initiative (K/DOQI) guidelines as "failure to maintain an extracorporeal blood flow sufficient to perform hemodialysis without significantly lengthening the hemodialysis treatment" [1], influencing stage 5 chronic kidney disease (CKD) patients' morbidity and mortality [2]. Among the causes of CDys, those occurring within the first 2 weeks of placement are defined as early dysfunction commonly resulting from mechanical problems, which include inadequate positioning, kinking, or constriction, while late dysfunction usually results from thrombus formation [1]. However, this case report demonstrates that one must also consider other causes of CDys.

\section{Case report}

A 63-year-old Caucasian female with a 6-year history of CKD5d of unknown etiology was referred for permanent hemodialysis access. She had a history of three failed fistula and prosthetic arteriovenous accesses (2 in the upper left extremity and 1 upper right extremity) with early recurrent thrombosis despite no evidence of underlying hypercoagulable state. The aforementioned difficulty in achieving vascular access (VA) prompted multiple catheter placement and multiple central vein stenosis (CVst) as shown by venography (occlusion of left internal jugular, left brachiocephalic, left subclavian, and right internal jugular veins, but patent right subclavian vein and superior vena cava). Facing dim venous capital and due to nonimmediate availability of $55 \mathrm{~cm}$ doublelumen tunneled cuffed (DLTC), a 40-cm long DLTC catheter was placed in the right femoral vein. However, despite seemingly adequate flow on aspiration and apparent positioning in the mid inferior vena cava (IVC), the catheter presented flow rates permanently below $200 \mathrm{~mL} / \mathrm{min}$. In spite of no clear technical or radiological complications, the flow rates displayed seemed unreasonably low. Given the circumstances, a contrast-enhanced thoraco-abdomino-pelvic computed tomography (CT) (Figure 1) was performed revealing absence of the IVC with common iliac veins draining directly into a prominent azygos vein. There were also multiple anomalies configuring a case of situs ambiguous (SA), such as partial inversion of abdominal
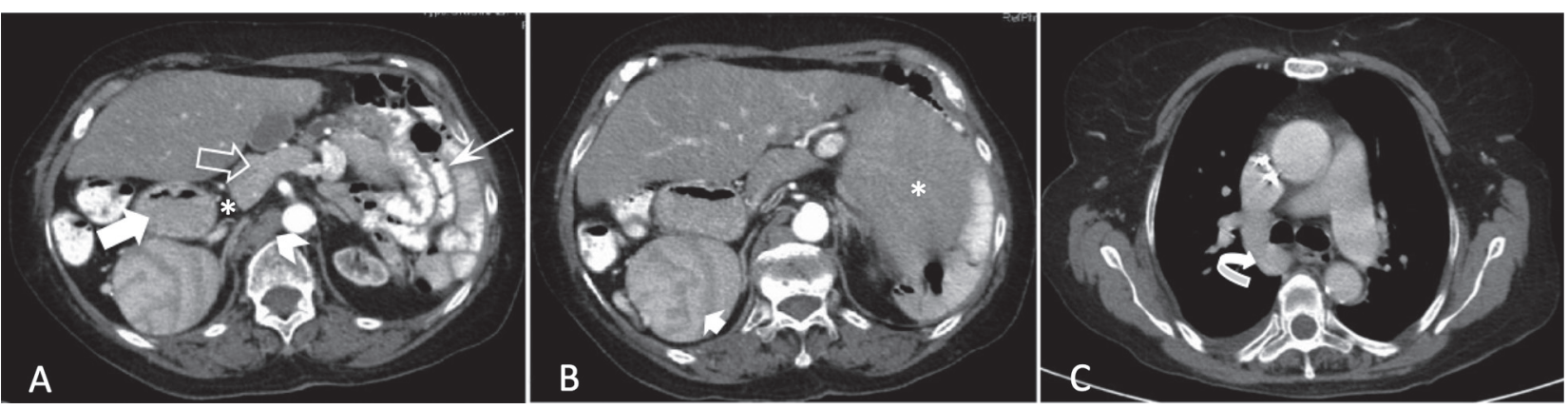

Figure 1. Thoraco-abdomino-pelvic computed tomography (CT): multiple anomalies. A: Absence of the IVC $\left(^{*}\right)$, with the common iliac veins draining directly into a prominent azygos vein (arrowhead), partial inversion of the abdominal viscera (heterotaxia) with right-sided stomach (solid arrow), right-sided pancreas (open arrow), and malrotation of the gastrointestinal tract (thin arrow) with inverse relationship between the superior mesenteric vessels (vein is located to the left of the artery). B: Unusual liver configuration with prominent left lobe $\left(^{*}\right)$ and right polysplenia ( 3 spleens, the larger - small arrow - measuring $6.5 \times 6.0 \mathrm{~cm}$ ). C: Enlarged azygos vein (curved arrow) at the confluence of the superior vena cava. 


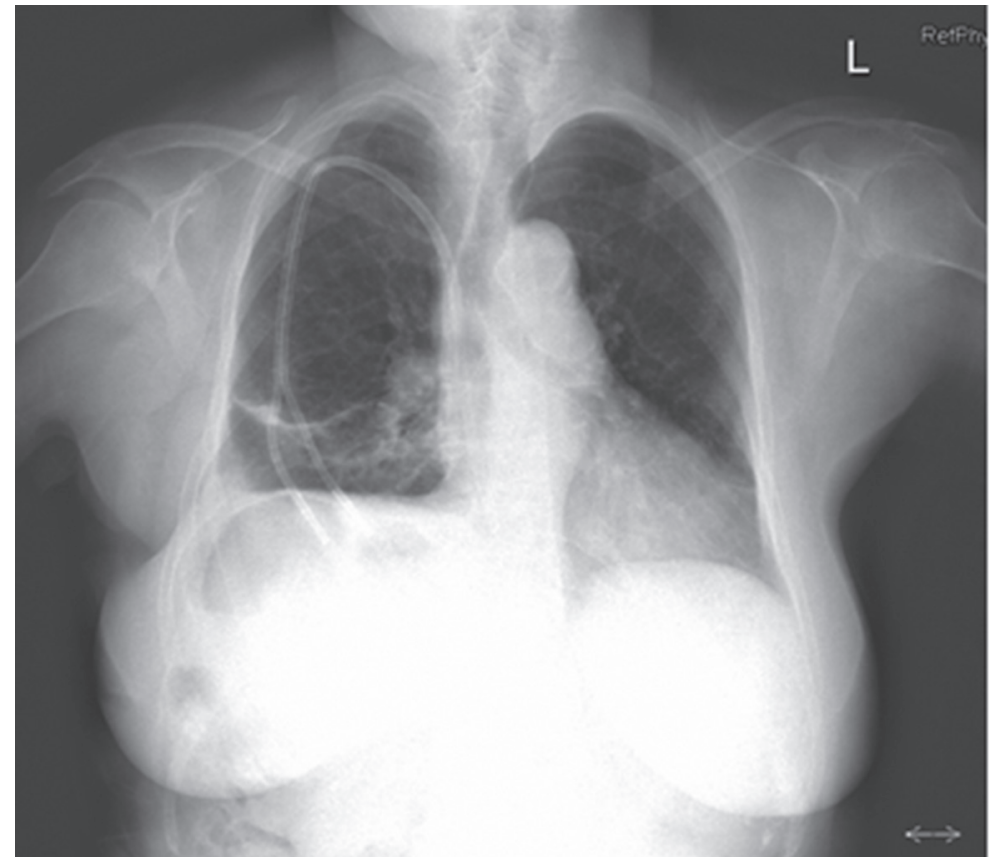

Figure 2. Posteroanterior chest radiograph (CXR): Prominence of pulmonary vasculature with no pleuroparenchymal abnormalities and normal hilar configuration. Normal mediastinal contours and cardiac silhouette except for aortic arch enlargement with circumferential calcification. Fluid level image beneath the right hemidiaphragm evidencing discordant position between the cardiac apex and gastric air bubble.

viscera (heterotaxia) with right-sided stomach and pancreas, right polysplenia, unusual liver configuration, and malrotation of the gastrointestinal tract. Reviewing past medical records, polysplenia had already been depicted on abdominal ultrasounds, but no other anomalies were described, and as for chest X-rays, surprisingly no heterotaxia was obvious as no gastric air bubble was clear on those available. Because of the need of adequate VA, and despite patent right upper arm venous drainage, mapping showed no possible autologous access, grafts seemed unreliable due to previous recurrent thrombosis history and angioplasty of CVst could not be achieved. A 24-cm long DLTC catheter was placed in the right subclavian vein under ultrasound and fluoroscopic guidance, complicated by a right hemothorax in the following 24 hours requiring drainage thoracentesis. No further complications were witnessed and the patient has been kept on hemodialysis for 13 months through the right subclavian DLTC (Figure 2), with no signs of CDys and with adequately delivered di- alysis dose, as estimated via the $\mathrm{Kt} / \mathrm{V}$ index (mean single-pool Kt/V of $1.94 \pm 0.20$ ).

\section{Discussion}

SA or heterotaxy syndrome is an anomaly where thoracic and abdominal organs are not clearly lateralized, as seen in situs solitus (normal position of heart and viscera) or in situs inversus. SA is usually associated with multiple abnormalities, including complex cardiovascular malformations as well as gastrointestinal and splenic abnormalities. In fact, splenic abnormalities are so defining that SA is usually categorized by the splenic morphology: 1) polysplenia (left isomerism, usually with multiple spleens) or 2) asplenia (right isomerism, with absence of spleen). The true incidence of SA is unknown but estimated at 2.5/100,000 live births [3]. However, the high incidence of severe cardiovascular malformations [4] prompts high mortality rates in early childhood and merely $5-10 \%$ reach adulthood - those with only minor or no cardiac abnormalities [5]. Among venous malformations, the congenital interruption of the IVC is the most frequently encountered in $\sim 80 \%$ of the cases [6], usually presenting as absence of the hepatic segment with azygos continuation [7]. However, in this case, there was a full IVC agenesis with azygos continuation. This has been previously reported in rare cases [6]. As for upper extremity venous drainage, there is usually no involvement nor are there described hypercoagulable states associated with SA, rendering it hard to explain the difficulties encountered in VA creation in this patient since the usual VA sites were patent. Nonetheless, given the aforesaid venous malformations involving IVC, using this site as VA would likely fail. Of note, despite having had previous short noncuffed catheters in the right femoral vein, this anomaly only became apparent when a longer femoral DLTC catheter was inserted.

On the other hand, isolated congenital anomalies of IVC are much more prevalent than SA. They range from $0.3 \%$ in otherwise healthy individuals [8] to $2 \%$ of patients with other cardiovascular defects [9]. They result from either embryonic dysontogenesis or, as some authors suggest, from intrauterine or perinatal thrombosis [10]. This explains 
the numerous reported cases of thrombotic events and hypercoagulable states associated with these anomalies. Consequently, the resulting clinical problems are easily predictable.

\section{Conflict of interest}

None declared.

\section{References}

[1] KDOQI Clinical Practice Guidelines for Vascular Access. Clinical Practice Guidelines for Vascular Access. Am J Kidney Dis. 2006; 48: S176-S247. CrossRef PubMed

[2] Lee T, Mokrzycki M, Moist L, Maya I, Vazquez M, Lok CE; North American Vascular Access Consortium. Standardized definitions for hemodialysis vascular access. Semin Dial. 2011; 24: 515-524. CrossRef PubMed

[3] Rose V, Izukawa T, Moёs CA. Syndromes of asplenia and polysplenia. A review of cardiac and noncardiac malformations in 60 cases withspecial reference to diagnosis and prognosis. Br Heart J. 1975; 37: 840-852. CrossRef PubMed

[4] Pepes S, Zidere V, Allan LD. Prenatal diagnosis of left atrial isomerism. Heart. 2009; 95: 1974-1977. CrossRef PubMed

[5] Peoples WM, Moller JH, Edwards JE. Polysplenia: a review of 146 cases. Pediatr Cardiol. 1983; 4: 129-137. CrossRef PubMed

[6] Applegate KE, Goske MJ, Pierce G, Murphy D. Situs revisited: imaging of the heterotaxy syndrome. Radiographics. 1999; 19: 837-852; discussion 853-834. PubMed

[7] Bartram U, Fischer G, Kramer HH. Congenitally interrupted inferior vena cava without other features of the heterotaxy syndrome: report of five cases and characterization of a rare entity. Pediatr Dev Pathol. 2008; 11: 266-273. PubMed

[8] Schneider JG, Eynatten MV, Dugi KA, Duex M Nawroth PP. Recurrent deep venous thrombosis caused by congenital interruption of the inferior vena cava and heterozygous factor $\mathrm{V}$ Leiden mutation. J Intern Med. 2002; 252: 276-280. CrossRef PubMed

[9] Vijayvergiya R, Bhat MN, Kumar RM, Vivekanand $S G$, Grover A. Azygos continuation of interrupted inferior vena cava in association with sick sinus syndrome. Heart. 2005; 91: e26. CrossRef PubMed

[10] Gil RJ, Pérez AM, Arias JB, Pascual FB, Romero $E S$. Agenesis of the inferior vena cava associated with lower extremities and pelvic venous thrombosis. J Vasc Surg. 2006; 44: 1114-1116. Cross$\underline{\text { Ref PubMed }}$

\section{Correspondence to}

Pedro Vieira, MD

Serviço de Nefrologia do Hospital Central do

Funchal, Avenida Luís de Camões N. ${ }^{\circ}$ 57,

9004-514 Funchal, Portugal

pedro.mds.vieira@gmail.com 